This item was submitted to Loughborough's Research Repository by the author.

Items in Figshare are protected by copyright, with all rights reserved, unless otherwise indicated.

\title{
A single session of treadmill running has no effect on plasma total ghrelin concentrations
}

PLEASE CITE THE PUBLISHED VERSION

PUBLISHER

(C) Taylor \& Francis

LICENCE

CC BY-NC-ND 4.0

\section{REPOSITORY RECORD}

Burns, Stephen F., David R. Broom, Masashi Miyashita, Claire Mundy, and David J. Stensel. 2019. "A Single Session of Treadmill Running Has No Effect on Plasma Total Ghrelin Concentrations". figshare. https://hdl.handle.net/2134/2815. 
This item was submitted to Loughborough's Institutional Repository by the author and is made available under the following Creative Commons Licence conditions.

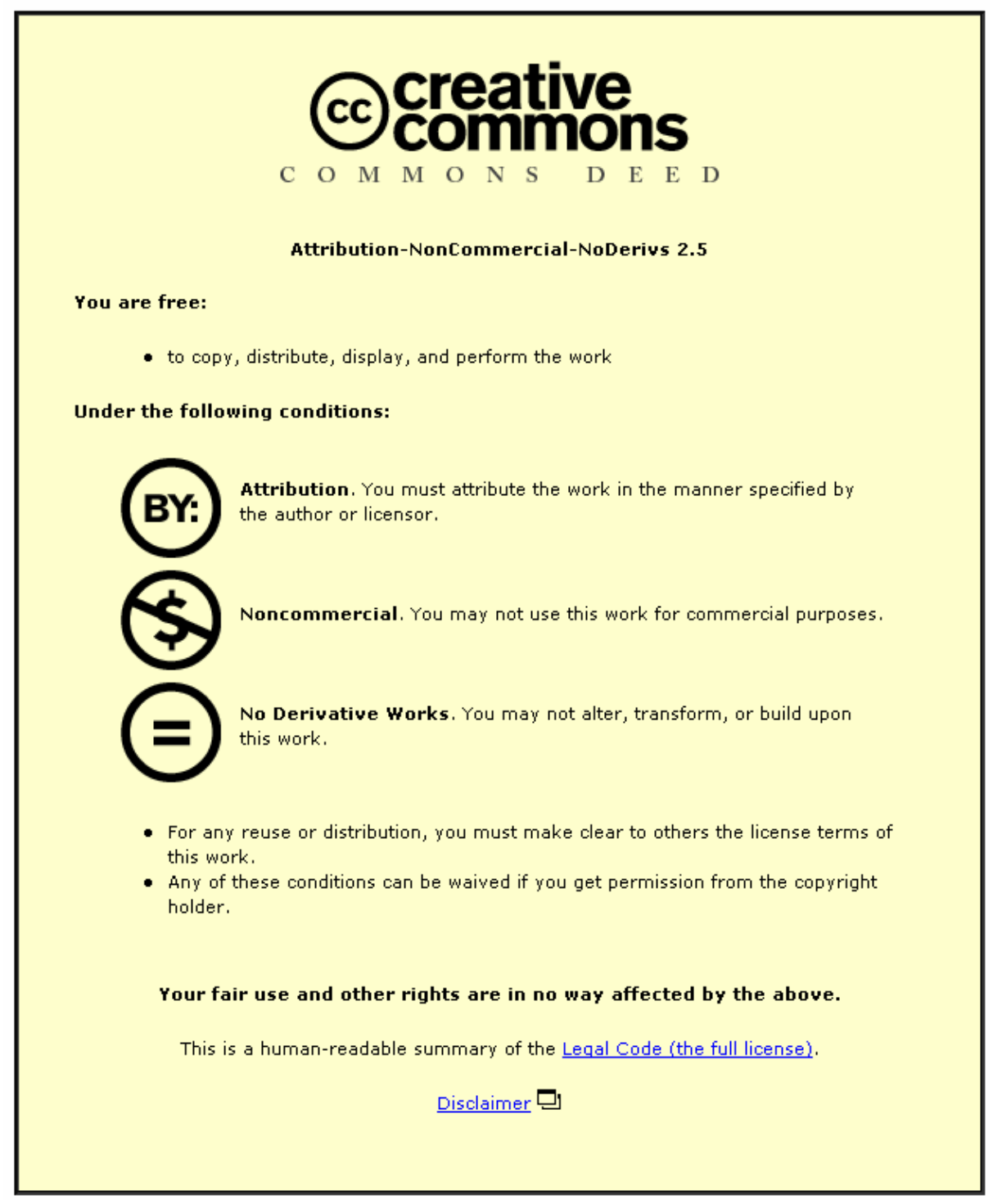

For the full text of this licence, please go to: http://creativecommons.org/licenses/by-nc-nd/2.5/ 
A single session of treadmill running has no effect on plasma total ghrelin concentrations

Stephen F Burns, David R Broom, Masashi Miyashita, Claire Mundy and David J

Stensel $(\bowtie)$

School of Sport and Exercise Sciences

Loughborough University

Loughborough

Leicestershire

LE11 3TU, UK

\section{Correspondence and requests for reprints:}

Dr David Stensel

School of Sport and Exercise Sciences

Loughborough University

Leicestershire

LE11 3TU, UK

Phone: $\quad$ +44 (0)1509 226344

Fax: $\quad$ +44 (0)1509226301

E-mail:_ D.J.Stensel@lboro.ac.uk

\section{Acknowledgements}

We thank all of the subjects who participated in this study. None of the authors have any conflict of interest regarding the findings reported in this study. 
A single session of treadmill running has no effect on plasma total ghrelin concentrations

Abbreviated Title: Treadmill running and plasma ghrelin

Key Words: hunger, appetite, exercise, weight control 


\section{Abstract}

2 Ghrelin is a hormone stimulating hunger. Intense exercise has been shown to

3 temporarily suppress hunger post-exercise. The present study investigated

4 whether post-exercise hunger suppression is mediated by reduced plasma

5 total ghrelin concentrations.

6

7 Nine men and nine women participated in this study. Age, body mass index

8 and maximal oxygen uptake ( $\mathrm{O}_{2}$ max ) of the participants (mean $\pm s_{\bar{X}}$ )

9 were: $24.8 \pm 0.9 \mathrm{yr}, 22.9 \pm 0.6 \mathrm{~kg} \cdot \mathrm{m}^{2}$ and $57.7 \pm 2.2 \mathrm{~mL} \cdot \mathrm{kg}^{-1} \cdot \mathrm{min}^{-1}$.

10 Participants completed two, three-hour trials (exercise and control) on

11 separate days in a randomised balanced design after overnight fasts. The

12 exercise trial involved a one-hour treadmill run at $73.5 \%$ of

13 max followed by two hours of rest. The control trial involved three

14 hours of rest. Blood samples were collected at 0, 0.5, 1, 1.5, 2 and 3 hours.

15 Total ghrelin concentrations were determined from plasma. Hunger was

16 assessed following blood samples using a 15-point scale. Data were analysed

17 via repeated measures ANOVA.

19 Hunger scores were lower in the exercise trial compared with the control trial

20 (Trial $\mathrm{P}=0.009$; Time $\mathrm{P}<0.001$; Interaction $\mathrm{P}<0.001$ ). Plasma total ghrelin

21 concentrations did not differ between trials.

23 These findings indicate that treadmill running suppresses hunger but this

24 effect is not mediated by changes in plasma total ghrelin concentration. 


\section{Introduction}

26 Ghrelin is a hormone that is secreted by the stomach and in smaller amounts

27 from the hypothalamus (Kojima et al., 1999). Ghrelin concentrations rise just

28 before meals and decrease rapidly after meals suggesting that ghrelin is

29 involved in the acute regulation of hunger (Ariyasu et al., 2001, Cummings et

30 al., 2001). This is supported by the finding that infusion of ghrelin leads to a

31 short-term increase in hunger in humans (Wren et al., 2001). Plasma total

32 ghrelin concentrations correlate negatively with body mass index (BMI)

33 (Ikezaki et al., 2002, Soriano-Guillen et al., 2004, Tschop et al., 2001) and

34 are responsive to diet and exercise induced changes in body mass (Cummings

35 et al., 2002, Foster-Schubert et al., 2005, Leidy et al., 2004) indicating that

36 ghrelin also has a role in regulating energy balance.

38 To our knowledge only four studies have examined the influence of an acute

39 bout of aerobic exercise on total plasma ghrelin (Dall et al., 2002, Kallio et

40 al., 2001, Kraemer et al., 2004a, Schmidt et al., 2004). The findings of these

41 studies are consistent and indicate that a single session of aerobic exercise

42 has no influence on total plasma ghrelin concentration. However, only one of

43 these studies employed a control trial (Kraemer et al., 2004a). Moreover, in

44 three of these studies the duration of exercise was relatively short ( $<30 \mathrm{~min}$ )

45 and none of these studies included an assessment of hunger.

47 There is evidence that intense exercise ( $>60 \%$ of $\mathrm{O}_{2}$ max $)$ causes a 48 temporary post-exercise suppression of hunger (King et al., 1994, King and 
49 Blundell, 1995.). This is possibly due to a decline in splanchnic blood flow

50 during exercise (Rowell, 1974) although other mechanisms may be

51 responsible. If it could be shown that exercise suppresses plasma total ghrelin

52 concentration and hunger simultaneously this would: a) support previous

53 research findings indicating that intense exercise suppresses hunger, b)

54 indicate a mechanism by which exercise and hunger are related. Exercise

55 may then be recommended as an alternative to pharmacological methods

56 (currently being developed) for lowering plasma total ghrelin concentration,

57 reducing hunger and controlling weight.

58

59 Therefore, in view of the limitations of current research we decided to re-

60 examine the relationship between exercise and plasma total ghrelin

61 concentration using a greater exercise stimulus (i.e. greater exercise intensity

62 and duration and therefore greater energy deficit) than has been examined

63 previously. We also sought to link changes in plasma total ghrelin

64 concentration with changes in feelings of hunger - this has not been

65 monitored in previous studies. Our primary hypothesis was that prolonged,

66 intense exercise ( 1 hour at $73.5 \%$ of $\mathrm{O}_{2}$ max ) would lead to a short-term

67 suppression of hunger which would be linked to suppressed plasma total

68 ghrelin concentration. A secondary hypothesis was that two hours after

69 exercise, hunger ratings and plasma total ghrelin concentrations would be

70 higher on the exercise compared with the control trial due to the energy

71 deficit created by the exercise. 


\section{Methods}

\section{Participants}

74 Eighteen healthy volunteers (nine male and nine female) aged 19-32 years

75 participated in this study, which was approved by the University's Ethical

76 Advisory Committee. The participants gave written informed consent after

77 receiving an explanation of the procedures and risks involved. Participants

78 completed a health screen questionnaire and a physical activity questionnaire.

79 Participants were recruited only if they met the following criteria: were non-

80 smoking, were not currently on a weight gain/weight loss diet and had not

81 been on any such diet during the previous six months, had maintained a

82 stable weight in the previous six months, had no gastric or digestive

83 problems, had no known history of cardiovascular disease, had resting

84 arterial blood pressure $<140 / 90 \mathrm{~mm} \mathrm{Hg}$.

85

86 Some physical characteristics of the participants are shown in Table 1. As a

87 group these individuals were highly fit (mean $\mathrm{O}_{2}$ max of 63 and 52

$88 \mathrm{~mL} \cdot \mathrm{kg}^{-1} \cdot \mathrm{min}^{-1}$ for men and women, respectively). All participants reported

89 that they were involved in some form of regular physical activity. The most

90 common form of activity was games sports (soccer, rugby, hockey,

91 basketball) but some participants also performed weight training and

92 recreational running.

93 


\section{Preliminary tests}

96 Anthropometry: Height was assessed using a Holtain fixed wall stadiometer

97 (Seca, Germany). Measurements were taken to the nearest $0.1 \mathrm{~cm}$. Body

98 mass was measured using a beam balance (Avery, Birmingham, U.K.).

99 Measurements were taken to the nearest $0.01 \mathrm{~kg}$. Skinfold thickness was

100 measured at four sites (triceps, biceps, subscapular and suprailiac) on the

101 right hand side of the body using calipers (John Bull, U.K.). Body density

102 was calculated using a four site formula and body fat percentage then

103 estimated using the Siri equation (Durnin and Womersley, 1974).

105 Submaximal treadmill test: A 16 minute, four-stage, submaximal treadmill 106 test was used to determine the relationship between running speed and 107 oxygen consumption. Initial running speed was set between 8 and $9 \mathrm{~km} \cdot \mathrm{h}^{-1}$ 108 depending upon participants' running ability. The treadmill was level 109 throughout the test. Speed was increased by between 1 and $1.6 \mathrm{~km} \cdot \mathrm{h}^{-1}$ every 4 110 minutes depending on participants' fitness. Expired air samples, heart rate 111 and ratings of perceived exertion (Borg, 1973) were collected during the final 112 minute of each stage. A linear regression equation was used to calculate the 113 relationship between running speed and oxygen consumption.

115 Maximum oxygen uptake test: $\mathrm{O}_{2}$ max was determined using an 116 incremental protocol in three-minute stages (Taylor et al., 1955). Treadmill 117 speed remained constant throughout the test. The initial incline of the 118 treadmill was 3.5\%. Treadmill gradient was increased by $2.5 \%$ every 3 
119 minutes. Expired air samples, heart rate and ratings of perceived exertion

120 were collected from 1:45 to 2:45 minutes of each stage and throughout the

121 final minute of the test. Participants determined the end point of the test by

122 indicating to the experimenters when they felt they could run for only one

123 further minute. The final expired air collection was started at that point.

124 Strong verbal encouragement was given to participants throughout the test.

125 Criteria for $\mathrm{O}_{2}$ max included two or more of the following: 1) heart rate

126 within $\pm 10 \mathrm{~b} \cdot \mathrm{min}^{-1}$ of age-predicted maximum heart rate, 2) a respiratory

127 exchange ratio value $\geq 1.15$, 3) a plateau in oxygen consumption.

129 Main trials

130 Two main trials (exercise or control) were performed in a counterbalanced,

131 randomised design. The interval between the two trials was at least one week.

132 For each trial the participants reported to the laboratory at 08.00 hours after a

133 10-hour overnight fast. A cannula was inserted into a forearm or antecubital

134 vein and the participants rested quietly for ten minutes. During this period

135 participants were asked to rate their hunger (see below). In the control trial

136 participants continued resting (reading, working quietly, watching television)

137 for the next three hours. In the exercise trial participants performed a one-

138 hour treadmill run (see below) and then rested for two hours.

140 Blood samples were obtained at baseline and at 0.5, 1, 1.5, 2 and 3 hours

141 after baseline. The cannula was kept patent by flushing with nonheparinised

142 saline (9 $\mathrm{g} \cdot \mathrm{L}^{-1}$, B.Braun Medical Ltd, Buckinghamshire, UK). The first $2 \mathrm{~mL}$ 
143 of blood withdrawn was always discarded to avoid dilution of the sample.

144 Participants were always lying in a supine position for at least five minutes

145 before blood samples were taken except for the 0.5 and 1 hour samples taken

146 during the exercise trial. For these samples participants straddled the

147 treadmill while blood was being drawn. This process took approximately one

148 minute. Water was available ad libitum during both trials and the volume

149 ingested was recorded. Hunger was reassessed at each blood sampling point.

\section{One-hour treadmill run}

152 Participants were instructed that the exercise was designed to be a 'hard run'

153 for one hour. Participants were initially set running at a speed calculated to

154 elicit $75 \%$ of their $\mathrm{O}_{2}$ max. If the run was too difficult for participants the

155 speed of the treadmill was lowered. However, the speed was still maintained

156 to produce a high intensity. Expired air samples were collected into $200 \mathrm{~L}$

157 Douglas bags (Plysu Protection Systems, Milton Keynes, U.K.) at 14-15, 29-

158 30, 44-45 and 59-60 minutes during the run. Heart rate was measured using

159 short-range telemetry (Polar Electro, OV), and ratings of perceived exertion

160 were recorded during collections of expired air. Oxygen consumption and

161 carbon dioxide production were determined from expired air samples using a

162 paramagnetic oxygen analyser and an infrared carbon dioxide analyser

163 (Servomex Analyser Series 1400; Servomex, Crowborough, East Sussex,

164 U.K.). Expired air volumes were measured using a dry gas meter (Harvard

165 Apparatus, Edenbridge, Kent, U.K.) and corrected to standard temperature 166 and pressure (dry). Energy expenditure during exercise, substrate utilisation, 
167 carbohydrate oxidation rate $\left(\mathrm{g} \cdot \mathrm{min}^{-1}\right)$ and fat oxidation rate $\left(\mathrm{g} \cdot \mathrm{min}^{-1}\right)$, were

168 calculated using equations for energy expenditure assuming no protein 169 oxidation (Frayn, 1983).

\section{Hunger scale}

172 A 15-point visual scale was used to assess hunger. Participants indicated their

173 perceived level of hunger by pointing to a number which best represented

174 how hungry they felt. The following phrases were included on the scale: not

175 hungry, fairly hungry, hungry and very hungry. The visual scale was

176 validated against the visual analogue scales developed by King and 177 colleagues (King et al., 1996, King et al., 1994). The responses were 178 identical.

\section{Control for diet and exercise}

181 For two days preceding the main trials participants were asked to replicate 182 their physical activity. Participants weighed and recorded all food and drink 183 consumed during the 48 hours immediately preceding their first trial and they 184 replicated this intake during the 48 hours prior to their second trial. 185 Participants were asked to refrain from alcohol consumption during these 186 periods. There was no control for menstrual cycle phase amongst female 187 participants in this study.

188

189 Analytical methods

190 At each sampling point, blood samples were collected into pre-cooled 9mL 
191 potassium-EDTA monovettes (Sarstedt Monovette Potassium EDTA 1.6mg

192 EDTA/mL blood, Sarstedt, Germany) that were kept on ice until

193 centrifugation (Koolspin Refrigerated Centrifuge, Burkard Scientific,

194 Uxbridge, Middlesex, U.K.). Plasma was separated within 15 min of

195 collection, divided into aliquots, and stored at $-80^{\circ} \mathrm{C}$.

197 Plasma samples were analysed for total ghrelin concentration by enzyme

198 immunoassay (Phoenix Pharmaceuticals) using a plate reader (Opsys

199 Microplate Reader, Dynex Technologies Inc., Franklin MA, U.S.). Glucose

200 (Randox Laboratories Ltd. U.K.) and NEFA (Wako Chemicals GmbH,

201 Germany) were analysed from plasma samples by enzymatic, colorimetric

202 methods using an automated centrifugal analyser (Cobas Mira Plus; Roche,

203 Basel, Switzerland). Plasma insulin concentration was determined using a

204 solid-phase ${ }^{125} \mathrm{I}$ radioimmunoassay available in a commercial kit (MP

205 Biomedicals, Orangeburg, NY, U.S.). Radioactivity was measured using an

206 automated gamma counting system (Cobra II, Packard Instrument, Downers

207 Grove, IL, U.S.). Haemoglobin concentration and haematocrit were

208 determined from blood samples collected at baseline and three hours so that

209 changes in plasma volume could be estimated (Dill and Costill, 1974). The

210 within batch coefficients of variation for the assays were as follows: ghrelin

$2119.6 \%$, glucose, 1.3\%, NEFA 0.8\%, insulin 5.7\%. To eliminate inter-assay

212 variation, samples from both trials for each participant were analysed in the

213 same batch. 


\section{Data analysis}

216 Results were analysed using statistical software (SPSS 11.0, SPSS Inc.,

217 Chicago, IL, U.S.). Fasting and area under the curve values were compared 218 between trials using $t$-tests for correlated data. Where gender comparisons 219 were required independent $t$-tests were used. Repeated measures two-way 220 ANOVA was used to determine differences between trials and over time for 221 measurements of hunger and plasma concentrations of total ghrelin. Where 222 appropriate post-hoc pair wise comparisons were made using the Bonferroni 223 method. Relationships between variables were evaluated using Pearson's 224 product-moment correlation coefficient. A 5\% level of significance was 225 adopted throughout, and data are expressed as mean $\pm s \bar{X}$. 


\section{Results}

\section{Responses to treadmill running}

228 Average heart rate during exercise was $173 \pm 2 \mathrm{~b} \cdot \mathrm{min}^{-1}$. This represented 91

$229 \pm 1 \%$ of maximum heart rate. The mean $\% \mathrm{O}_{2}$ max elicited during exercise

230 was $73.5 \pm 0.8 \%$ and the mean respiratory exchange ratio was $0.89 \pm 0.01$.

231 Gross energy expenditure during exercise was $3747 \pm 207 \mathrm{~kJ}$ with $35 \pm 3 \%$ of

232 energy provided from fat and $64 \pm 3 \%$ of energy provided from carbohydrate.

233 The median rating of perceived exertion during exercise was 15 i.e. 'hard'

234 (range 13-16).

\section{Fluid consumption and body mass}

237 Participants consumed more water $(P<0.001)$ during the exercise trial $(978 \pm$

$238115 \mathrm{~mL})$ compared to the control trial $(443 \pm 76 \mathrm{~mL})$. Body mass did not

239 differ between trials at baseline. Body mass was lower $(P=0.006)$ at the end 240 of the exercise trial (i.e. at 3 hours) compared with the end of the control trial

241 (67.9 $\pm 2.6 \mathrm{~kg}$ versus $68.5 \pm 2.6 \mathrm{~kg}$ for exercise and control respectively).

\section{Hunger}

244 Hunger scores (Figure 1) were suppressed during and after exercise: main 245 effect of trial $(P=0.009)$, main effect of time $(P<0.001)$, trial $\times$ time 246 interaction $(P<0.001)$. Post-hoc tests revealed that hunger scores were lower 247 during the exercise versus control trial at 0.5, 1, 1.5 and 2 hours (all $P<0.05$ ).

248 There was a main effect of time and a trial $\times$ time interaction for both sexes 
249 for hunger. However a main effect of trial was not found for either sex in

250 isolation. Males: trial $P=0.059$, time $P<0.001$, trial $\times$ time interaction

$251 P=0.022$; females: trial $P=0.100$, time $P<0.001$, trial $\times$ time interaction $252 P=0.004$.

\section{Hormone and substrate concentrations at baseline}

257 Baseline plasma concentrations are shown in Tables 2 and 3. There were no

258 differences between the control and exercise trials for any of the 259 hormones/metabolites at baseline. Although baseline plasma total ghrelin

260 concentrations tended to be higher for the males than the females on both the 261 control and exercise trials these differences were not significant ( $P=0.52$ and $262 P=0.54$ for the control and exercise trials respectively).

\section{Hormone and substrate responses to exercise}

265 Changes in plasma volume over the period of observation were small and did 266 not differ $(P=0.865)$ between control $(-0.6 \pm 1.7 \%)$ and exercise $(0.0 \pm 3.3 \%)$

267 trials. Therefore, no adjustments were made to measured concentrations of 268 plasma constituents.

270 There was no significant difference in plasma total ghrelin concentrations 271 between trials or over time in either the group as a whole (Figure 2) or the 272 males or females separately. Area under the curve values for plasma total 
273 ghrelin concentration did not differ significantly between the exercise and

274 control trials for the males, the females or the group as a whole (Table 2).

275 Although the area under the curve values tended to be higher for males than

276 females on both the control and the exercise trials these gender differences

277 were not significant ( $P=0.457$ for the control trial and $P=0.302$ for the

278 exercise trial, $t$-tests for correlated data).

279

280

TABLE 2 NEAR HERE

281

FIGURE 2 NEAR HERE

282

283 Area under the curve values for insulin, glucose and NEFA are shown in

284 Table 3. Area under the curve values for NEFA and glucose were higher on

285 the exercise than the control trial for the group as a whole ( $P=0.007$ for

286 NEFA, $P=0.004$ for glucose).

287

288

TABLE 3 NEAR HERE

289

290 Mean fasting plasma total ghrelin concentrations (i.e. control trial

291 concentration plus exercise trial concentration divided by two) were not

292 significantly correlated with BMI, body mass, body fat percentage, waist

293 circumference, insulin, glucose or $\mathrm{O}_{2}$ max for the group as a whole. For the

294 males a negative correlation between fasting plasma total ghrelin

295 concentration and BMI was observed ( $r=-0.726, P=0.027)$ and both body fat

296 percentage $(r=-0.626, P=0.071)$ and waist circumference $(r=-0.606, P=0.084)$ 
297 showed a trend toward significant negative correlations with plasma total 298 ghrelin concentration. No significant correlations were observed between 299 fasting plasma total ghrelin concentration and any of the above variables for 300 the females. 
302 The main finding in the present study is that hunger was suppressed during

303 and after treadmill running whereas plasma total ghrelin concentration was

304 unaffected. The lack of change in plasma total ghrelin concentration during

305 aerobic exercise is consistent with the findings of previous studies (Dall et

306 al., 2002, Kallio et al., 2001, Kraemer et al., 2004a, Schmidt et al., 2004).

307 However, the present study extends the findings of these studies by showing

308 that plasma total ghrelin concentrations are unrelated to feelings of hunger

309 during and following exercise, which has not been examined previously.

311 The volume of exercise performed in the present study would have induced a

312 greater energy deficit compared to that in previous studies (Dall et al., 2002,

313 Kallio et al., 2001, Kraemer et al., 2004a, Kraemer et al., 2004b, Schmidt et

314 al., 2004). We employed a high volume and intensity of exercise for two

315 reasons. Firstly, we attempted to provoke a temporary suppression of hunger

316 which we thought might be linked to suppressed concentrations of plasma

317 total ghrelin. Secondly, we hypothesised that the large energy deficit (3747

$318 \mathrm{~kJ}=$ approximately $900 \mathrm{kcal}$ ) would result in an elevated plasma total ghrelin

319 concentration two hours post exercise when feelings of hunger had returned

320 and possibly increased. Support for this notion comes from the finding that

321 plasma total ghrelin concentration is elevated in women who are in a state of

322 chronic energy deficit as evidenced by amenorrhoea or anorexia (De Souza et

323 al. 2004, Otto et al. 2001). In the present study, the elevated NEFA

324 concentrations on the exercise trial suggest that participants were in an acute 
325 state of negative energy balance compared with the control trial. However,

326 there was no evidence that plasma total ghrelin concentrations were increased

327 at any point in the exercise trial.

329 The suppressed hunger ratings observed in the present study lasted for at least

330 one hour post-exercise. There was no difference in hunger at the start or end

331 of the trials in the present study, thus the suppression in hunger seen here

332 suggests a temporary exercise-induced anorexia (King et al., 1994, King and

333 Blundell, 1995). It is known that during exercise there is redistribution of

334 blood flow away from the splanchnic circulation towards the working

335 muscles (Rowell, 1974). Since ghrelin is produced in the stomach (Kojima et

336 al., 1999) and blood flow to this region is reduced during exercise we

337 speculated that ghrelin concentrations would also be reduced. Another reason

338 for expecting exercise induced suppression of ghrelin is that exercise

339 increases growth hormone secretion (Schmidt et al 2004) and this is thought

340 to down regulate ghrelin secretion (Korbonits et al 2004). However, ghrelin

341 may stimulate changes in hunger via afferent activity of the vagus nerve

342 (Hosoda et al. 2002). Therefore, it is possible that exercise could influence

343 hunger by altering ghrelin signalling through the vagus nerve without

344 changing circulating ghrelin concentrations.

346 Plasma ghrelin concentrations have been shown to change in response to

347 individual meals (Ariyasu et al., 2001, Cummings et al., 2001), although this

348 is not a universal finding (English et al., 2002) and at least one study has 
349 demonstrated a preservation of meal related ghrelin responses in subjects

350 who fasted for 24 hours (Natalucci et al. 2005). The acute change in ghrelin

351 following food intake was one factor that led us to hypothesize that plasma

352 total ghrelin concentration might respond acutely to exercise. However, food

353 intake could influence ghrelin concentrations via mechanisms that are less

354 applicable to exercise.

355

356 The presence of nutrients in the gut (Caixas et al., 2002) and increases in

357 insulin (Flanagan et al., 2003) and glucose (Nakagawa et al., 2002)

358 concentrations in the blood have all been associated with reductions in

359 plasma total ghrelin concentration. Such changes do not necessarily occur

360 during or following an acute bout of exercise. Plasma insulin concentrations,

361 for example, were unaffected by exercise in the present study although

362 plasma glucose concentrations were elevated. Moreover, short-term (4-day)

363 energy restriction (-3360 kJ/d) has been found to have no effect on fasting

364 and postprandial plasma total ghrelin concentrations (Doucet et al., 2004).

365 Therefore, perhaps plasma total ghrelin concentrations are more sensitive to

366 acute changes in nutrient intake than to acute physiological changes

367 (redistribution of blood flow, short-term energy deficit) induced by exercise.

369 Some studies have reported that plasma total ghrelin concentrations are 370 negatively correlated with BMI, body fat percentage and waist circumference

371 (Ikezaki et al., 2002, Tschop et al., 2001). In the present study BMI was

372 negatively correlated with plasma total ghrelin concentration in the male 
373 group. Moreover, body fat percentage and waist circumference showed a

374 trend towards a significant negative correlation with plasma total ghrelin

375 concentration in the males. Possibly the range of values was too narrow in

376 the present study to produce statistically significant correlations. However,

377 the trends in the present study for males support previous evidence that

378 plasma total ghrelin concentration is related to body composition.

380 The present study did not control for menstrual cycle phase between trials for

381 female participants. No study has systematically investigated plasma total

382 ghrelin concentration changes over the course of the menstrual cycle.

383 However, Barkan and colleagues (2003) reported that plasma total ghrelin

384 concentration (measured in the late follicular stage of the menstrual cycle)

385 was higher in five young women compared to six young men. Conversely,

386 Tschop and colleagues found no sex differences for plasma total ghrelin

387 concentration in either Caucasians or Pima Indians (Tschop et al., 2001).

388 Similarly, Purnell and co-workers reported that fasting plasma total ghrelin 389 concentrations did not differ in 21 male and 39 female healthy subjects

390 (Purnell et al., 2003). Our findings are consistent with these studies in

391 indicating that plasma total ghrelin concentrations do not differ significantly

392 between men and women.

393

394 Although the findings of the present study concur with the evidence currently

395 available regarding exercise and plasma total ghrelin concentration, caution is

396 required when interpreting the results. Ghrelin is also released in small 
397 amounts within the central nervous system and acts directly on the

398 hypothalamus (Kojima et al., 1999). This was not measured in the present

399 study and it is possible that ghrelin release within the central nervous system

400 differed between the control and exercise trials. Furthermore, ghrelin

401 circulates in both active and inactive forms in the plasma (Kojima et al.,

402 1999). The present study measured total plasma ghrelin concentrations (i.e.

403 active and inactive combined) and not active ghrelin. Active ghrelin is more

404 sensitive to changes in energy intake than total ghrelin (Hosoda et al., 2004)

405 and it is possible that active ghrelin may respond to exercise. Nevertheless,

406 previous studies have demonstrated changes in plasma total ghrelin

407 concentration in response to meals (Ariyasu et al., 2001, Cummings et al.,

408 2001) suggesting that changes in total ghrelin do reflect changes in active

409 ghrelin in some situations.

410

411 In conclusion our findings indicate that a one-hour bout of high intensity

412 treadmill running leads to a temporary suppression of hunger. However, this

413 effect does not appear to be mediated through a decrease in plasma total

414 ghrelin concentration. This suggests that plasma total ghrelin concentration is

415 not responsive to acute exercise induced alterations in metabolism. 
418 Ariyasu, H., Takaya, K., Tagami, T., Ogawa, Y., Hosoda, K., Akamizu, T.,

419 Suda, M., Koh, T., Natsui, K., Toyooka, S., Shirakami, G., Usui, T.,

420 Shimatsu, A., Doi, K., Hosoda, H., Kojima, M., Kangawa, K. and Nakao, K.

421 (2001). Stomach is a major source of circulating ghrelin, and feeding state

422 determines plasma ghrelin-like immunoreactivity levels in humans. Journal

423 of Clinical Endocrinology \& Metabolism, 86, 4753-4758.

425 Barkan, A. L., Dimaraki, E. V., Jessup, S. K., Symons, K. V., Ermolenko, M.

426 and Jaffe, C. A. (2003). Ghrelin secretion in humans is sexually dimorphic,

427 suppressed by somatostatin, and not affected by the ambient growth hormone

428 levels. Journal of Clinical Endocrinology \& Metabolism, 88, 2180-2184.

430 Borg, G. A. (1973). Perceived exertion: a note on "history" and methods.

431 Medicine and Science in Sports, 5, 90-93.

433 Caixas, A., Bashore, C., Nash, W., Pi-Sunyer, F. and Laferrere, B. (2002).

434 Insulin, unlike food intake, does not suppress ghrelin in human subjects. The

435 Journal of Clinical Endocrinology \& Metabolism, 87, 1902-1906.

437 Cummings, D. E., Purnell, J. Q., Frayo, R. S., Schmidova, K., Wisse, B. E.

438 and Weigle, D. S. (2001). A preprandial rise in plasma ghrelin levels

439 suggests a role in meal initiation in humans. Diabetes, 50, 1714-1719. 
440 Cummings, D. E., Weigle, D. S., Frayo, R. S., Breen, P. A., Ma, M. K.,

441 Dellinger, E. P. and Purnell, J. Q. (2002). Plasma ghrelin levels after diet-

442 induced weight loss or gastric bypass surgery. New England Journal of

443 Medicine, 346, 1623-1630.

444

445 Dall, R., Kanaley, J., Hansen, T. K., Moller, N., Christiansen, J. S., Hosoda,

446 H., Kangawa, K. and Jorgensen, J. O. (2002). Plasma ghrelin levels during

447 exercise in healthy subjects and in growth hormone-deficient patients.

448 European Journal of Endocrinology, 147, 65-70.

449

450 De Souza, M.J., Leidy, H.J., O’Donnell, E., Lasley, B. and Williams, N.I.

451 (2004). Fasting ghrelin levels in physically active women: relationship with

452 menstrual disturbances and metabolic hormones. Journal of Clinical

453 Endocrinology and Metabolism, 89, 3536-3542.

454

455 Dill, D. B. and Costill, D. L. (1974). Calculation of percentage changes in

456 volumes of blood, plasma, and red cells in dehydration. Journal of Applied

457 Physiology, 37, 247-248.

458

459 Doucet, E., Pomerleau, M. and Harper, M. E. (2004). Fasting and

460 postprandial total ghrelin remain unchanged after short-term energy

461 restriction. Journal of Clinical Endocrinology \& Metabolism, 89, 1727-

4621732.

463 
464 Durnin, J. V. G. A. and Womersley, J. (1974). Body fat assessed from total 465 body density and its estimation from skinfold thickness: measurements on 466481 men and women aged from 16 to 72 years. British Journal of Nutrition, $467 \quad 32,77-97$.

469 English, P. J., Ghatei, M. A., Malik, I. A., Bloom, S. R. and Wilding, J. P. 470 (2002). Food fails to suppress ghrelin levels in obese humans. Journal of 471 Clinincal Endocrinology and Metabolism, 87, 2984-2987.

473 Flanagan, D. E., Evans, M. L., Monsod, T. P., Rife, F., Heptulla, R. A., 474 Tamborlane, W. V. and Sherwin, R. S. (2003). The influence of insulin on 475 circulating ghrelin. American Journal of Physiology Endocrinology and 476 Metabolism, 284, E313-316.

478 Foster-Schubert, K. E., McTiernan, A., Frayo, R. S., Schwartz, R. S., Rajan, 479 K. B., Yasui, Y., Tworoger, S. S. and Cummings, D. E. (2005). Human 480 plasma ghrelin levels increase during a one-year exercise program. Journal of 481 Clinical Endocrinology and Metabolism, 90, 820-825.

483 Frayn, K. N. (1983). Calculation of substrate oxidation rates in vivo from 484 gaseous exchange. Journal of Applied Physiology, 55, 628-634. 485

486 Hosoda, H., Doi, K., Nagaya, N., Okumura, H., Nakagawa, E., Enomoto, M., 487 Ono, F. and Kangawa, K. (2004). Optimum collection and storage conditions 
488 for ghrelin measurements: octanoyl modification of ghrelin is rapidly

489 hydrolyzed to desacyl ghrelin in blood samples. Clinical Chemistry, 50,

$490 \quad 1077-1080$.

491

492 Hosoda, H., Kojima, M. and Kangawa, K. (2002). Ghrelin and the regulation

493 of food intake and energy balance. Molecular Interventions, 2, 494-503.

494

495 Ikezaki, A., Hosoda, H., Ito, K., Iwama, S., Miura, N., Matsuoka, H., Kondo,

496 C., Kojima, M., Kangawa, K. and Sugihara, S. (2002). Fasting plasma ghrelin

497 levels are negatively correlated with insulin resistance and PAI-1, but not

498 with leptin, in obese children and adolescents. Diabetes, 51, 3408-3411.

499

500 Kallio, J., Pesonen, U., Karvonen, M. K., Kojima, M., Hosoda, H., Kangawa,

501 K. and Koulu, M. (2001). Enhanced exercise-induced GH secretion in

502 subjects with Pro7 substitution in the prepro-NPY. Journal of Clinical

503 Endocrinology and Metabolism, 86, 5348-5352.

504

505 King, N. A. and Blundell, J. E. (1995). High-fat foods overcome the energy

506 expenditure induced by high-intensity cycling or running. European Journal

507 of Clinical Nutrition, 49, 114-123.

508

509 King, N. A., Burley, V. J. and Blundell, J. E. (1994). Exercise-induced

510 suppression of appetite: effects on food intake and implications for energy

511 balance. European Journal of Clinical Nutrition, 48, 715-724. 
512 King, N. A., Snell, L., Smith, R. D. and Blundell, J. E. (1996). Effects of

513 short-term exercise on appetite responses in unrestrained females. European

514 Journal of Clinical Nutrition, 50, 663-667.

515

516 Kojima, M., Hosoda, H., Date, Y., Nakazato, M., Matsuo, H. and Kangawa,

517 K. (1999). Ghrelin is a growth-hormone-releasing acylated peptide from

518 stomach. Nature, 402, 656-660.

519

520 Korbonits, M., Goldstone, A.P., Gueorguiev, M. and Grossman, A.B. (2004).

521 Ghrelin - a hormone with multiple functions. Frontiers in

522 Neuroendocrinology, 25, 27-68.

523

524 Kraemer, R. R., Durand, R. J., Acevedo, E. O., Johnson, L. G., Kraemer, G.

525 R., Hebert, E. P. and Castracane, V. D. (2004a). Rigorous running increases

526 growth hormone and insulin-like growth factor-I without altering ghrelin.

527 Experimental Biology and Medicine (Maywood), 229, 240-246.

528

529 Kraemer, R. R., Durand, R. J., Hollander, D. B., Tryniecki, J. L., Hebert, E.

530 P. and Castracane, V. D. (2004b). Ghrelin and other glucoregulatory

531 hormone responses to eccentric and concentric muscle contractions.

532 Endocrine, 24, 93-98.

533

534 Leidy, H. J., Gardner, J. K., Frye, B. R., Snook, M. L., Schuchert, M. K.,

535 Richard, E. L. and Williams, N. I. (2004). Circulating ghrelin is sensitive to 
536 changes in body weight during a diet and exercise program in normal-weight

537 young women. Journal of Clinical Endocrinology and Metabolism, 89, 2659-

5382664.

539

540 Nakagawa, E., Nagaya, N., Okumura, H., Enomoto, M., Oya, H., Ono, F.,

541 Hosoda, H., Kojima, M. and Kangawa, K. (2002). Hyperglycaemia

542 suppresses the secretion of ghrelin, a novel growth-hormone-releasing

543 peptide: responses to the intravenous and oral administration of glucose.

544 Clinical Science (London), 103, 325-328.

545

546 Natalucci G, Riedl S, Gleiss A, Zidek T, Frisch H. (2005). Spontaneous 24-h

547 ghrelin secretion pattern in fasting subjects: maintenance of a meal-related

548 pattern. European Journal of Endocrinology, 152, 845-500.

550 Otto, B., Cuntz, U., Fruehauf, E., Wawarta, R., Folwaczny, C., Riepl, R.L.,

551 Heiman, M.L., Lehnert, P., Fichter, M. and Tschöp, M. (2001). Weight gain

552 decreases elevated plasma ghrelin concentrations of patients with anorexia

553 nervosa. European Journal of Clinical Endocrinology, 145, R5-R9.

555 Purnell, J. Q., Weigle, D. S., Breen, P. and Cummings, D. E. (2003). Ghrelin

556 levels correlate with insulin levels, insulin resistance, and high-density

557 lipoprotein cholesterol, but not with gender, menopausal status, or cortisol

558 levels in humans. Journal of Clinical Endocrinology and Metabolism, 88, $559 \quad 5747-5752$. 
560 Rowell, L. B. (1974). Human cardiovascular adjustments to exercise and

561 thermal stress. Physiological Reviews, 54, 75-159.

562

563 Schmidt, A., Maier, C., Schaller, G., Nowotny, P., Bayerle-Eder, M.,

564 Buranyi, B., Luger, A. and Wolzt, M. (2004). Acute exercise has no effect on

565 ghrelin plasma concentrations. Hormone and Metabolic Research, 36, 174-

566177.

567

568 Soriano-Guillen, L., Barrios, V., Campos-Barros, A. and Argente, J. (2004).

569 Ghrelin levels in obesity and anorexia nervosa: effect of weight reduction or

570 recuperation. The Journal of Pediatrics, 144, 36-42.

571

572 Taylor, H. L., Buskirk, E. and Henschel, A. (1955). Maximal oxygen intake

573 as an objective measure of cardio-respiratory performance. Journal of

574 Applied Physiology, 8, 73-80.

575

576 Tschop, M., Weyer, C., Tataranni, P. A., Devanarayan, V., Ravussin, E. and

577 Heiman, M. L. (2001). Circulating ghrelin levels are decreased in human

578 obesity. Diabetes, 50, 707-709.

579

580 Wren, A. M., Seal, L. J., Cohen, M. A., Brynes, A. E., Frost, G. S., Murphy,

581 K. G., Dhillo, W. S., Ghatei, M. A. and Bloom, S. R. (2001). Ghrelin

582 enhances appetite and increases food intake in humans. Journal of Clinical

583 Endocrinology and Metabolism, 86, 5992-5995. 


\section{$584 \quad$ Figure Captions}

585

586 Figure 1. Subjective feelings of hunger in the fasted state over 3 hours

587 during exercise and control trials. Values are mean $\pm s \bar{x}, n=18$. Main effect

588 of trial $(P=0.009)$, main effect of time $(P<0.001)$, trial $\times$ time interaction

589 ( $P<0.001)$. *Significantly different $(P<0.05)$ between trials using a

590 Bonferroni post hoc test.

591

592 Figure 2. Plasma total ghrelin concentrations in the fasted state over 3 hours

593 during exercise and control trials. No significant main effects. No significant

594 interaction. Values are mean $\pm s_{\bar{X}}, n=18$. 
Table 1. Physical characteristics of the subjects.

\begin{tabular}{|c|c|c|c|}
\hline & Males $(n=9)$ & Females $(n=9)$ & $P$ \\
\hline Age (yrs) & $24.5 \pm 1.3$ & $25.1 \pm 1.2$ & 0.737 \\
\hline Height (m) & $1.78 \pm 0.02$ & $1.68 \pm 0.02$ & 0.007 \\
\hline Body mass (kg) & $74.03 \pm 4.20$ & $63.57 \pm 2.55$ & 0.049 \\
\hline $\mathrm{BMI}\left(\mathrm{kg} \cdot \mathrm{m}^{2}\right)$ & $23.4 \pm 1.0$ & $22.5 \pm 0.8$ & 0.501 \\
\hline Waist circumference (cm) & $79 \pm 3$ & $76 \pm 1$ & 0.324 \\
\hline Body fat (\%) & $16.9 \pm 1.7$ & $28.3 \pm 1.2$ & 0.001 \\
\hline $\mathrm{O}_{2} \max \left(\mathrm{mL} \cdot \mathrm{kg}^{-1} \cdot \mathrm{min}^{-1}\right)$ & $63.2 \pm 2.5$ & $52.1 \pm 2.4$ & 0.006 \\
\hline
\end{tabular}


Table 2. Baseline and three-hour areas under the plasma total ghrelin concentration versus time curve (AUC) during the control and exercise trials.

\begin{tabular}{lccc}
\hline & Control & Exercise & $P$ \\
\hline Baseline Ghrelin & & & \\
Whole Group $\left(\mathrm{pmol} \cdot \mathrm{L}^{-1}\right)$ & $412.2 \pm 75.6$ & $410.2 \pm 66.8$ & 0.910 \\
Males $\left(\mathrm{pmol} \cdot \mathrm{L}^{-1}\right)$ & $463.1 \pm 144.0$ & $453.1 \pm 130.6$ & 0.664 \\
& & & \\
Females $\left(\mathrm{pmol} \cdot \mathrm{L}^{-1}\right)$ & $361.4 \pm 54.1$ & $367.3 \pm 38.1$ & 0.840 \\
\hline
\end{tabular}

Ghrelin 3-hour AUC

Whole Group $\left(\mathrm{pmol} \cdot \mathrm{L}^{-1} \cdot 3 \mathrm{~h}\right) \quad 1374.9 \pm 231.7 \quad 1240.7 \pm 179.8 \quad 0.189$

Males $\left(\mathrm{pmol} \cdot \mathrm{L}^{-1} \cdot 3 \mathrm{~h}\right) \quad 1556.1 \pm 440.6 \quad 1431.9 \pm 326.5 \quad 0.383$

Females $\left(\mathrm{pmol} \cdot \mathrm{L}^{-1} \cdot 3 \mathrm{~h}\right) \quad 1193.7 \pm 160.5 \quad 1049.5 \pm 147.2 \quad 0.366$

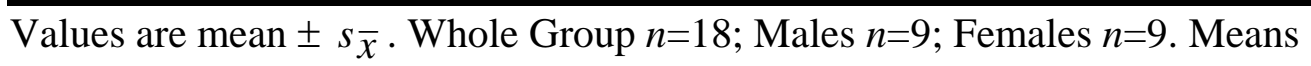

were compared using $t$-tests for correlated data. 
Table 3. Baseline and three-hour areas under the plasma concentration versus time curve (AUC) for insulin, NEFA and glucose during the control and exercise trials.

\begin{tabular}{lccc}
\hline & Control & Exercise & $P$ \\
\hline Baseline & & & \\
Insulin $\left(\mathrm{pmol} \cdot \mathrm{L}^{-1}\right)$ & $158.8 \pm 12.0$ & $168.9 \pm 12.5$ & 0.455 \\
NEFA $\left(\mathrm{mmol} \cdot \mathrm{L}^{-1}\right)$ & $0.51 \pm 0.05$ & $0.53 \pm 0.06$ & 0.799 \\
Glucose $\left(\mathrm{mmol} \cdot \mathrm{L}^{-1}\right)$ & $5.27 \pm 0.16$ & $5.49 \pm 0.18$ & 0.273 \\
\hline 3-hour AUC & & & \\
Insulin $\left(\mathrm{pmol} \cdot \mathrm{L}^{-1} \cdot 3 \mathrm{~h}\right)$ & $494.0 \pm 33.7$ & $492.6 \pm 35.0$ & 0.962 \\
NEFA $\left(\mathrm{mmol} \cdot \mathrm{L}^{-1} \cdot 3 \mathrm{~h}\right)$ & $1.67 \pm 0.17$ & $2.29 \pm 0.22$ & 0.007 \\
& & & 0.004 \\
\hline
\end{tabular}

Values are mean $\pm s_{\bar{\chi}}, n=18$. Means were compared using $t$-tests for correlated data. NEFA: non-esterified fatty acids. 